\title{
Design of Quad-Channel Diplexer and Tri-Band Bandpass Filter Based on Multiple-Mode Stub-Loaded Resonators
}

\author{
Sugchai TANTIVIWAT, Siti Zuraidah IBRAHIM, Mohammad Shahrazel RAZALLI
}

School of Computer and Communication Engineering, Universiti Malaysia Perlis, Arau 02600, Perlis, Malaysia

sugchai.t@rmutsv.ac.th, sitizuraidah@unimap.edu.my, shahrazel@unimap.edu.my

Submitted August 20, 2018 / Accepted December 20, 2018

\begin{abstract}
Multiple-mode stub-loaded resonator with quadchannel diplexer and tri-band bandpass filter are presented and analyzed theoretically in this paper. The multi-mode stub-loaded resonator employs the basic structure of a triplemode resonator. Herein, the triple-mode resonator is modified by introducing a mid-coupled line between the odd-mode resonances to produce a quad-mode resonator. The proposed resonator is applied in the quad-channel diplexer design, composing of two independent dual-band bandpass filters. In turn, the triple-band bandpass filter based on a parallel quadmode and a dual-mode stub-loaded resonator is developed. To validate the performance of the proposed resonators, two experimental examples, including a quad-channel diplexer and a triple-band bandpass filter are fabricated and measured. Each of the designed circuits occupies small area, i.e. about $0.32 \lambda_{\mathrm{g}} \times 0.22 \lambda_{\mathrm{g}}$ and $0.18 \lambda_{\mathrm{g}} \times 0.20 \lambda_{\mathrm{g}}$ respectively. Good agreements between simulated and measured results are achieved.
\end{abstract}

\section{Keywords}

Stub-loaded resonator, multi-mode resonator, diplexer, multi-band BPF

\section{Introduction}

Multiple-band bandpass filters (BPFs) and diplexers are the important and essential components of modern multiband communication systems. High performance microwave multi-band multi-service devices are highly required for the next generation of wireless communication systems. To meet this requirement, dual-mode and multiple-mode resonators have been extensively studied [1-3]. Several approaches to obtain a multi-band microstrip BPFs and diplexers are available through recent research. Some popular methods reported in the literature include the multiple-mode stub loaded resonators. In [4-6], the dual-band BPFs are achieved by implementing the dual-mode stub loaded resonators. Subsequently, triple-band BPFs is accomplished by cascading two stub-loaded resonators having similar structures [7-9].
Using this approach, its fractional bandwidth is dependent on the distance between resonators, hence the passband frequencies are unable to be tuned individually. The work in [10] presented that the two set of dual-mode resonator and half-wavelength resonators can be used to achieve triband BPF performance with compact size. In [11-12], the dual- and triple-band BPFs based on multiple-mode stubloaded resonator are presented by employing a single resonator. Thus, compact BPF configurations can be obtained. Since the multi-band BPF construction composed of an open stub-loaded shorted stepped-impedance, it is generally difficult to individually tune the resonant frequencies for each passband and meet the desired specifications of the coupling matrixes simultaneously. A quad-mode stub-loaded resonators are introduced in [13-14] to design multiband BPFs, where the passband frequencies and bandwidths can be individually adjusted.

Additionally, a diplexer is also an important component in RF front-end systems for channel separation of both the transmitter and receiver. In general, a diplexer is a device to combine two bandpass filters, which are operating at different passbands. In [15-16], a common resonator is employed to yield significant size reduction of the established multiplexer. The multi-channel diplexers have shown great potential for the development of advanced multiservice wireless communication systems. Several studies have been developed on the quad-channel diplexers. In [17-18], two sets of dual-mode stub loaded resonators and stepped impedance resonators are presented. The quad-channel diplexer that composed of two pairs of coupled short-circuited stub loaded resonators have been demonstrated in [19] but they increased the passband insertion loss.

In this paper, multiple-mode stub loaded resonators with basic triple- and quadruple-mode are proposed and analyzed theoretically. The proposed resonators are designed for the application of quad-channel diplexer, composed of two dualband BPFs of different operating frequencies. Additionally, the proposed resonators are combined with a dual-mode resonator to achieve a triple-band BPF. The two resonators share a common via hole at the midpoint of the short-ended stubs, hence three passband can be independently controlled bandwidth at each passband without affecting each others. 


\section{Quad-Mode Resonators}

To establish the independent resonators design of each passband response, the triple-mode resonator is initially proposed as shown in Fig. 1. In the inset of Fig. $1, Z_{1}, Z_{2}$ and $Z_{3}$ denote the characteristic impedances of the transmission lines and short-circuited stub sections with the lengths of $L_{1}, L_{2}$ and $L_{3}$, the width of $W_{1}, W_{2}$ and $W_{3}$, respectively. The structure in Fig. 1 is symmetrical, allowing for the odd- and even-mode analysis. Under odd-mode excitation, the symmetrical plane in Fig. 1 behaves as an electrical wall, thus the odd-mode equivalent circuit can be described as shown in Fig. 2(a). Under even-mode excitation, the symmetrical plane behaves as a magnetic wall, so the even-mode equivalent circuit can be described as shown in Fig. 3(a). Since the structure in Fig. 2(a) and Fig. 3(a) are also symmetric, each of the layout is further split to two modes, denoted as Path-I and Path-II. As can be seen, the circuits in Fig. 2(b) and Fig. 3(b) are the same, and thus they correspond to the same mode $\left(\operatorname{odd}_{1}=\operatorname{even}_{1}\right)$. Thus, this is a tri-mode resonator as shown in Fig. 1 with three controllable frequencies $\left(f_{\text {odd }_{1}}=f_{\text {even }_{1}}, f_{\text {odd }_{2}}, f_{\text {even }_{2}}\right)$.

The result of input impedance $Z_{\text {in,odd }_{1}}$ in Fig. 2(b) and $Z_{\text {in,even }}$ in Fig. 3(b) can be expressed as

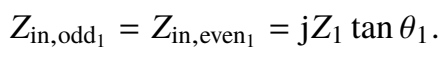

Therefore the path-I resonance condition of odd- and even-mode $Z_{\text {in,odd }_{1}}=Z_{\text {in,even }_{1}}=\infty$, we obtain the answer of $\theta_{1}=\pi / 2$, where $\theta_{1}=\beta L_{1}$ is the electrical length of the quarterwave-length resonator. The fundamental $f_{\text {odd }_{1}}$ and $f_{\text {even }}$ resonant frequency can be expressed as

$$
f_{\mathrm{odd}_{1}}=f_{\mathrm{even}_{1}}=\frac{\mathrm{c} \theta_{1}}{2 \pi L_{1} \sqrt{\varepsilon_{\mathrm{eff}}}}=\frac{\mathrm{c}}{4 L_{1} \sqrt{\varepsilon_{\mathrm{eff}}}} .
$$

The result of the path-II input impedance for odd-mode $\left(Z_{\text {in,odd }}\right)$ in Fig. 2(c) can be expressed as

$$
Z_{\text {in,odd }}=Z_{1} \frac{Z_{1} \tan \left(\theta_{1}\right)+2 Z_{2} \tan \left(\theta_{2}\right)}{\mathrm{j} 2 Z_{2} \tan \left(\theta_{1}\right) \tan \left(\theta_{2}\right)-Z_{1}} .
$$

From the resonance condition of $Z_{\text {in, } \text { odd }_{2}}=\infty$, we obtain the following equation

$$
\tan \left(\theta_{1}\right) \tan \left(\theta_{2}\right)=\frac{Z_{1}}{2 Z_{2}}
$$

Furthermore, some special case $2 Z_{2}=Z_{1}$ is assumed, the path-II fundamental odd-mode resonant frequency $\left(f_{\text {odd }_{2}}\right)$ can be expressed as

$$
f_{\text {odd }_{2}}=\frac{\mathrm{c}}{4\left(L_{1}+L_{2}\right) \sqrt{\varepsilon_{\text {eff }}}} .
$$

For simplicity, this special cases is assumed in Fig. 3(c). In the case of $2 Z_{2}=4 Z_{3}$, the result of the input impedance for path-II even-mode $Z_{\text {in,even }_{2}}$ can be expressed as

$$
Z_{\text {in,even } 2}=Z_{1} \frac{Z_{1} \tan \left(\theta_{1}\right)+2 Z_{2} \tan \left(\theta_{2}+\theta_{3}\right)}{\mathrm{j} 2 Z_{2} \tan \left(\theta_{1}\right) \tan \left(\theta_{2}+\theta_{3}\right)-Z_{1}} .
$$

The even-mode resonance condition of $Z_{\text {in,even }_{2}}=\infty$, we obtain the following equation

$$
\tan \left(\theta_{1}\right) \tan \left(\theta_{2}+\theta_{3}\right)=\frac{Z_{1}}{2 Z_{2}}
$$

Furthermore, some special case $Z_{1}=2 Z_{2}=4 Z_{3}$ is assumed, the fundamental path-II even-mode resonant frequency $\left(f_{\text {even }_{2}}\right)$ can be expressed as

$$
f_{\text {even }_{2}}=\frac{\mathrm{c}}{4\left(L_{1}+L_{2}+L_{3}\right) \sqrt{\varepsilon_{\text {eff }}}}
$$

where $\theta=\beta L$ is the electrical length, $\mathrm{c}$ is the light speed in free space, and $\varepsilon_{\text {eff }}$ denotes the effective dielectric constant of the substrate.

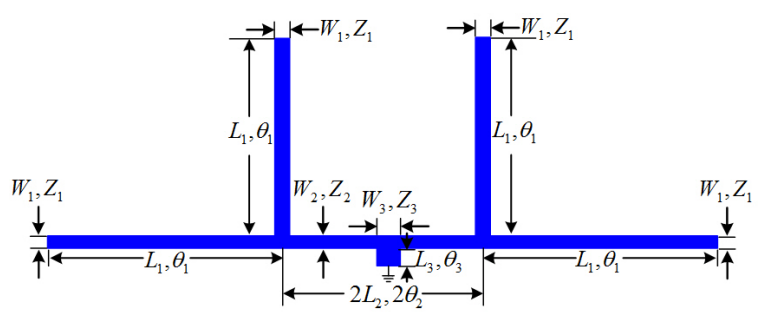

Fig. 1. Layout of the preliminaly triple-mode resonator.

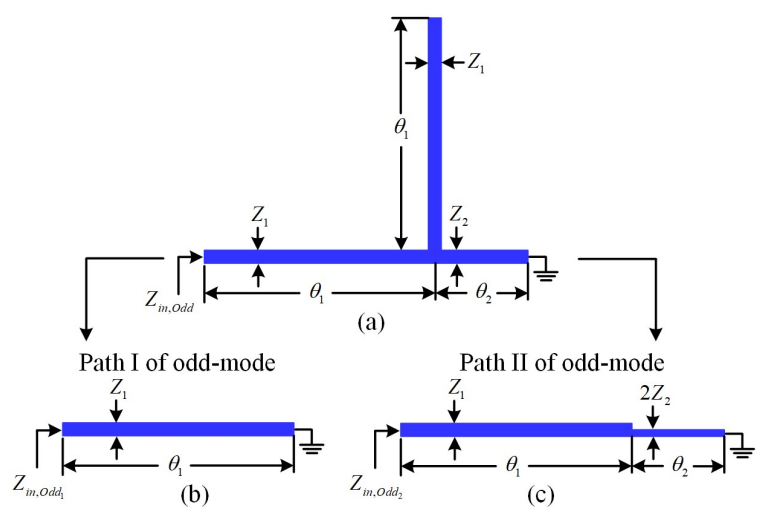

Fig. 2. The different resonant frequencies of odd-mode.

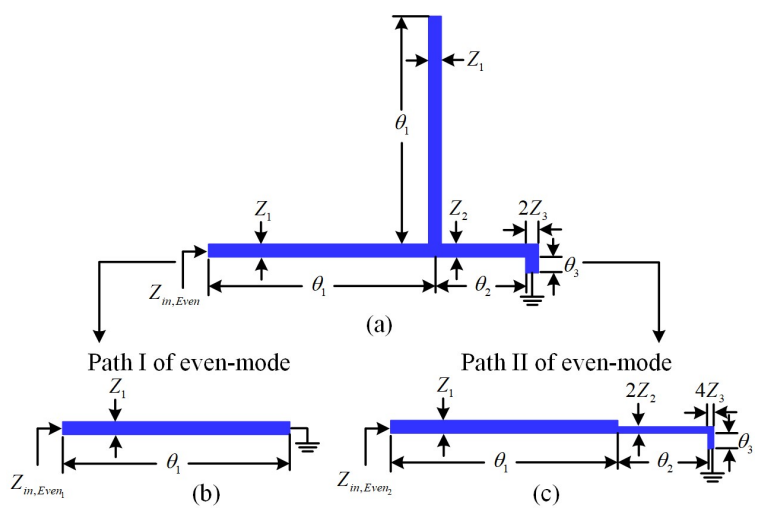

Fig. 3. The different resonant frequencies of even-mode. 


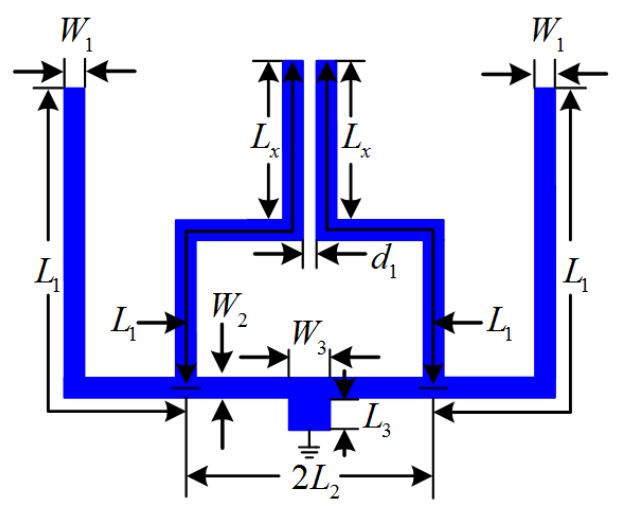

(a) Layout of the quad-mode resonator.

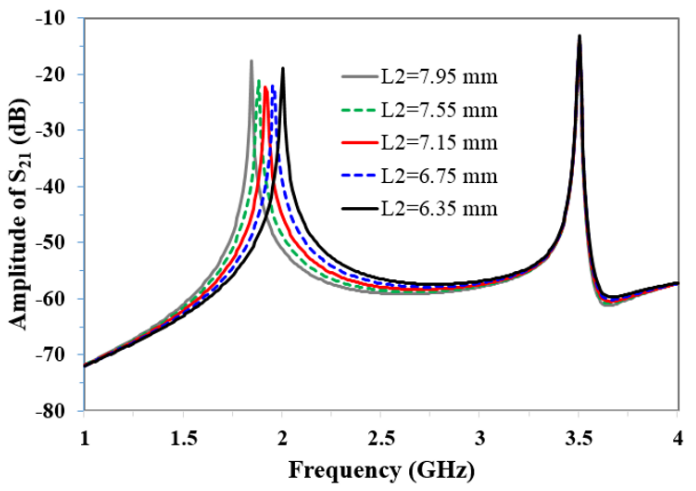

(b) Operating frequencies against the stub length $L_{2}$.

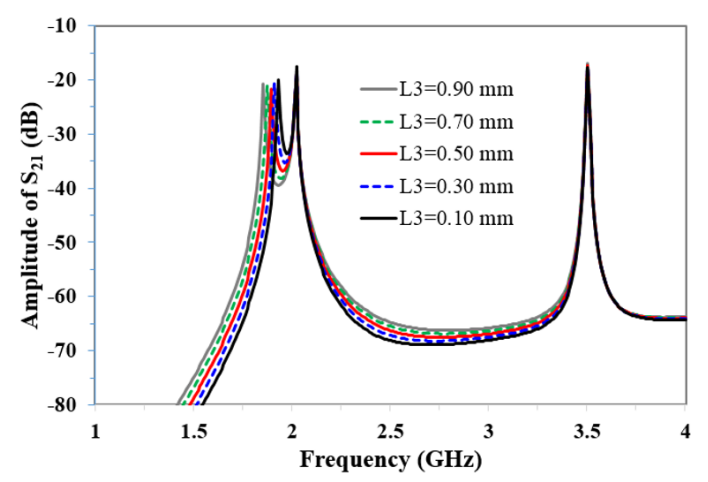

(c) Operating frequencies against the stub length $L_{3}$.

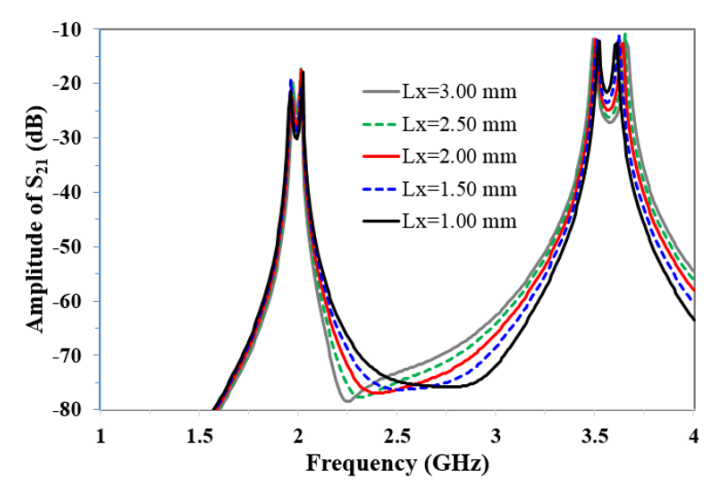

(d) Operating frequencies against the stub length $L_{x}$.

Fig. 4. Layout and the simulation $\left(S_{21}\right)$ of quad-mode resonator.
Another advantage of this resonator, it can be applied to produce a quad-mode resonator as shown in Fig. 4. The odd-mode is separated into two modes, the length of $L_{1}$ provides the first odd-mode resonant frequency and the second odd-mode resonant frequency are controlled by the coupling strength, determined by the parameter $L_{x}$. As can be seen in Fig. 4(a), the two halfwave-length resonators (inner stub $L_{1}$ ) are coupled together in the middle of the structure with the length $L_{x}$, as a result creates another odd-mode resonant frequency. The resonator shown in Fig. 4(a) is the modification of the compact quad-mode stub loaded resonator.

From (2), (5), and (8), the resonant frequencies of the first and second passband can be obtained. In summary, the length of $L_{1}$ affect the responses at all resonant frequencies. Therefore, the first step in designing a quad-mode resonator is to obtain the length of $L_{1}$, which is $\lambda_{\mathrm{g}} / 4$ at the odd-mode resonance frequency. Since the length of $L_{2}$ stub does not affect the response at the path-I odd-mode resonant frequency $\left(f_{\text {odd }_{1}}\right)$, therefore the resonant frequency of the path-II odd-mode $\left(f_{\text {odd }_{2}}\right)$ can be electrically tuned using $L_{2}$ parameter. The initial analysis begins by assuming the structure in Fig. 1 without the stub $L_{3}$. Fig. 4(b) shows the simulated response of $S_{21}$ by varying $L_{2}$. As depicted in Fig. 4(b), the $f_{\text {odd }_{1}}$ is remains stationary at $3.50 \mathrm{GHz}$, but the $f_{\mathrm{odd}_{2}}$ is shifted from $1.8 \mathrm{GHz}$ to $2.0 \mathrm{GHz}$ when $L_{2}$ decreases from $7.95 \mathrm{~mm}$ to $6.35 \mathrm{~mm}$.

In the second step, the whole structure in Fig. 1 is considered. In this step, the short-circuited stub of $L_{3}$ in Fig. 1 is optimized. The $L_{3}$ parameter can be easily adjusted to shift the second even-mode resonant frequency $\left(f_{\text {even } 2}\right)$. This approach can be used to generate triple-mode resonant frequencies. Fig. 4(c) shows the simulated response of $S_{21}$ by varying the length of stub $L_{3}$. As depicted in Fig. 4(c), the $f_{\text {even2 }}$ is shifted to the lower frequency when the length $L_{3}$ increases from $0.10 \mathrm{~mm}$ to $0.90 \mathrm{~mm}$, whereas the other resonant frequencies, $f_{\mathrm{odd}_{1}}$ and $f_{\mathrm{odd}_{2}}$ are remain unchanged.

In the final step, the quad-mode stub-loaded resonator structure in Fig. 4(a) is considered. The length of coupled line, $L_{x}$ is varied to achieve the second odd-mode frequency. Fig. 4(d) shows the simulated response of $S_{21}$ by varying the length of stub $L_{x}$. The length $L_{x}$ is adjusted from $1.00 \mathrm{~mm}$ to $3.00 \mathrm{~mm}$, while the gap is fixed at $d_{1}=0.30 \mathrm{~mm}$. The resonant mode frequencies of $f_{\mathrm{odd}_{1}}$ and $f_{\mathrm{even}}$ are shifted to the lower and higher in the passband while the path-II of oddand even-mode resonant frequencies are almost unaffected.

\section{Design of a Quad-Channel Diplexer}

Based on the quad-mode stub loaded resonator analyzed in the previous section, a compact quad-channel diplexer is designed as shown in Fig. 5. The diplexer is designed on a substrate Diclade Arlon 880 substrate with a relative dielectric constant of 2.20 , a thickness of $0.80 \mathrm{~mm}$, and a loss tangent of 0.009 . The specification of the second-order BPFs are designed for multiband wireless communication system to operate (Resonator 1) at $1.85 \mathrm{GHz}$ for $4 \mathrm{G} \mathrm{LTE}$ and 
2.45 GHz for WLAN, (Resonator 2) at $2.15 \mathrm{GHz}$ for UMTS and $3.50 \mathrm{GHz}$ for WiMAX. The fractional bandwidths are $5.40 \%, 4.08 \%, 4.65 \%$, and $5.71 \%$, respectively. Two microstrip lines with $50 \Omega$ characteristic impedance are used to feed the suggested quad-mode resonator by using loose coupling. Generally, a stronger coupling can be obtained with a smaller gap $\left(g_{1}, g_{2}\right)$. Thus a high impedance and longer coupled-line where the gap or length of feed line $\left(L_{\mathrm{f}}\right)$ are varied, external quality factor $\left(Q_{\mathrm{e}}\right)$ of the input and output coupled lines are adjusted to achieve the given bandwidth specification as shown in Fig. 6. A full-wave simulator is used to extract the $Q_{\mathrm{e}}$, where the width of feed port input $\left(W_{\mathrm{f}}\right)$ are fixed at $0.90 \mathrm{~mm}$. The geometric parameters are approximately obtained as $L_{\mathrm{f} 1}=20.75, L_{\mathrm{f} 2}=20.75, L_{\mathrm{f} 3}=19.75$, $g_{1}^{I}=g_{1}^{I I}=g_{2}^{I}=g_{2}^{I I}=0.30, d_{1}^{I}=0.40$, and $d_{1}^{I I}=0.30$ (All dimensions are in $\mathrm{mm}$ ), where the superscripts I and II denote the first path (Resonator 1) and second path (Resonator 2) of four passbands. The proposed quad-channel diplexer is designed with parameters listed in Tab. 1.

The simulated and measured results of the quad-channel diplexer, including the isolation between filter ports, are shown in Fig. 7. The measured passband return losses are better than $12 \mathrm{~dB}$ for four channels. The passband insertion losses are approximately 1.70 and $1.25 \mathrm{~dB}$ at $1.85 \mathrm{GHz}$ and $2.45 \mathrm{GHz}$. As for the another filter at $2.15 \mathrm{GHz}$ and $3.50 \mathrm{GHz}$, the passband insertion losses are approximately $2.30 \mathrm{~dB}$ and $0.65 \mathrm{~dB}$ respectively. The measured isolation is better than $20 \mathrm{~dB}$ since first passband response of Resonator 2 is located in the middle with nearby dual-passband of Resonator 1 . In summary, the measured results are in good agreement with the full-wave simulation results. From the photograph of the fabricated diplexer, the overall size of the fabricated circuit is $38.25 \times 26.25 \mathrm{~mm}$, i.e., about $0.32 \lambda_{\mathrm{g}} \times 0.22 \lambda_{\mathrm{g}}$, where $\lambda_{\mathrm{g}}$ is the guided wavelength on the substrate at the center frequency of channel 1 . Table 2 summarizes the comparison of the proposed diplexer with the previous works.

\begin{tabular}{|c|c|c|}
\hline & Resonator 1 & Resonator 2 \\
\hline $\begin{array}{l}\text { Higher frequency of } \\
\text { odd-mode }(\mathrm{GHz})\end{array}$ & 2.50 & 3.60 \\
\hline $\begin{array}{l}\text { Lower frequency of } \\
\text { odd-mode }(\mathrm{GHz})\end{array}$ & 2.40 & 3.40 \\
\hline $\begin{array}{l}\text { Higher frequency of } \\
\text { even-mode }(\mathrm{GHz})\end{array}$ & 1.90 & 2.20 \\
\hline $\begin{array}{l}\text { Lower frequency of } \\
\text { even-mode }(\mathrm{GHz})\end{array}$ & 1.80 & 2.10 \\
\hline $\begin{array}{c}\text { Impedance } \\
Z_{1}, Z_{2}, Z_{3}(\Omega)\end{array}$ & $\begin{array}{c}83.81,83.81, \\
56.75\end{array}$ & $\begin{array}{c}83.81,83.81, \\
56.75\end{array}$ \\
\hline $\begin{array}{c}\text { Length of } \\
L_{1}, L_{2}, L_{3}(\mathrm{~mm})\end{array}$ & $\begin{array}{c}22.70,1.75 \\
0.90\end{array}$ & $\begin{array}{c}15.70,3.15 \\
0.90\end{array}$ \\
\hline $\begin{array}{c}\text { Width of } \\
W_{1}, W_{2}, W_{3}(\mathrm{~mm})\end{array}$ & $\begin{array}{l}1.00,1.00 \\
2.00\end{array}$ & $\begin{array}{l}1.00,1.00 \\
2.00\end{array}$ \\
\hline Length of $L_{x}(\mathrm{~mm})$ & 9.00 & 9.60 \\
\hline
\end{tabular}

Tab. 1. Design parameters of quad-channel diplexer.

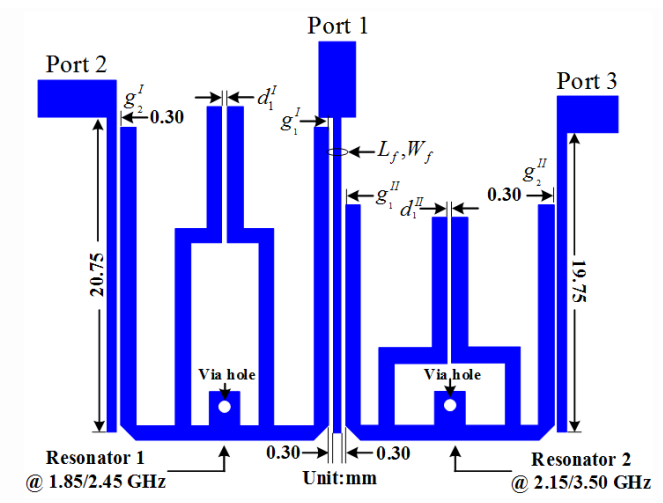

Fig. 5. Configuration of quad-channel diplexer.

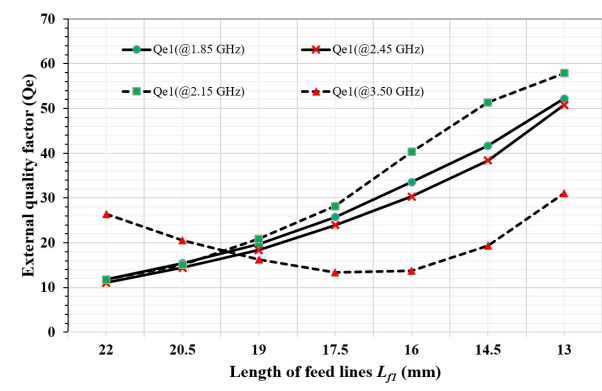

(a) extracted $Q_{\mathrm{e}}$ for input port 1 .

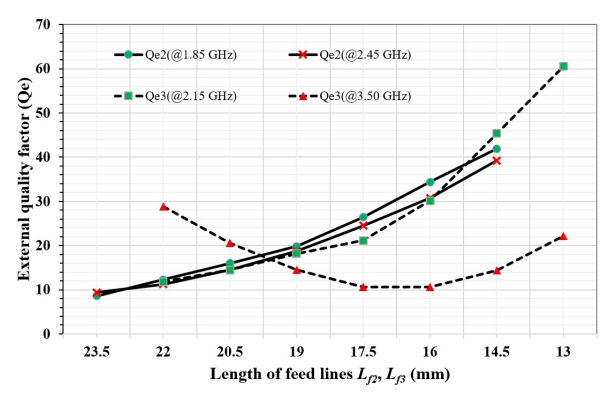

(b) extracted $Q_{\mathrm{e}}$ for output port 2 and 3.

Fig. 6. Simulated $Q_{\mathrm{e}}$ versus length of feed line $\left(L_{\mathrm{f}}\right)$ with fixed coupling gap $\left(g_{1}, g_{2}=0.3 \mathrm{~mm}\right)$.

\begin{tabular}{|c|c|c|c|c|}
\hline Ref. & $\mathrm{L} / \mathrm{C}$ & CF (GHz) & IL (dB) & $\begin{array}{c}\text { Size } \\
\left(\lambda_{\mathrm{g}} \times \lambda_{\mathrm{g}}\right)\end{array}$ \\
\hline [2] & $2 / 6$ & $\begin{array}{l}1.57 / 1.8 \\
/ 2.4 / 3.5 \\
/ 5.2 / 5.8\end{array}$ & $\begin{array}{c}1.5 / 1.1 \\
/ 1.5 / 1.2 \\
/ 2 / 2\end{array}$ & $0.17 \times 0.16$ \\
\hline [17] & $2 / 4$ & $\begin{array}{c}1.5 / 2 \\
2.4 / 3.5\end{array}$ & $\begin{array}{c}0.8 / 1 \\
/ 0.7 / 1.5\end{array}$ & $0.19 \times 0.40$ \\
\hline [18] & $2 / 4$ & $\begin{array}{c}0.6 / 0.9 \\
/ 1.22 / 1.58\end{array}$ & $\begin{array}{c}3.2 / 2.6 \\
/ 2.7 / 2.2\end{array}$ & $0.27 \times 0.16$ \\
\hline [19] & $2 / 4$ & $\begin{array}{c}2.5 / 3 \\
13.5 / 4\end{array}$ & $\begin{array}{l}2.49 / 2.5 \\
/ 2.9 / 2.4\end{array}$ & $0.48 \times 0.19$ \\
\hline $\begin{array}{l}\text { This } \\
\text { work }\end{array}$ & $2 / 4$ & $\begin{array}{c}1.85 / 2.45 \\
/ 2.15 / 3.50\end{array}$ & $\begin{array}{c}1.7 / 1.2 \\
/ 2.3 / 0.65\end{array}$ & $0.32 \times 0.22$ \\
\hline
\end{tabular}

Tab. 2. Comparisons with other proposed multi-channel diplexers (L/C: Number of load/channels, CF: Center frequency, IL: Insertion loss). 


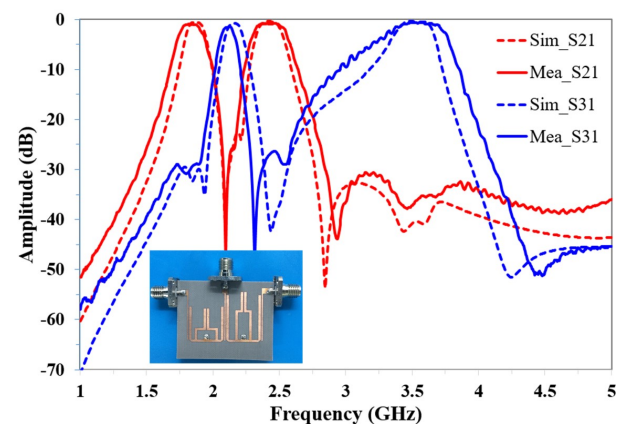

(a) Comparison of insertion loss $\left(S_{21}, S_{31}\right)$ response of the diplexer.

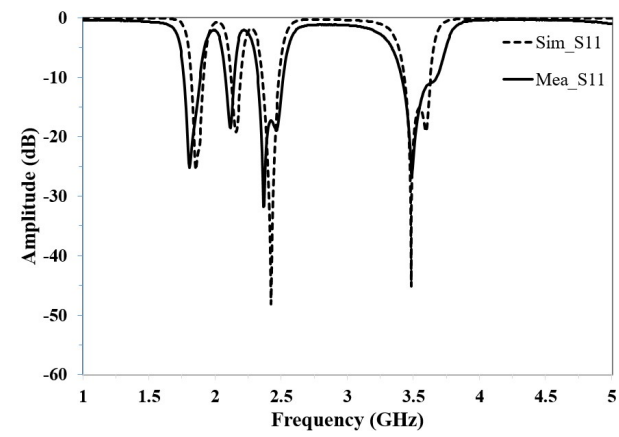

(b) Comparison of return loss $\left(S_{11}\right)$ response of the diplexer.

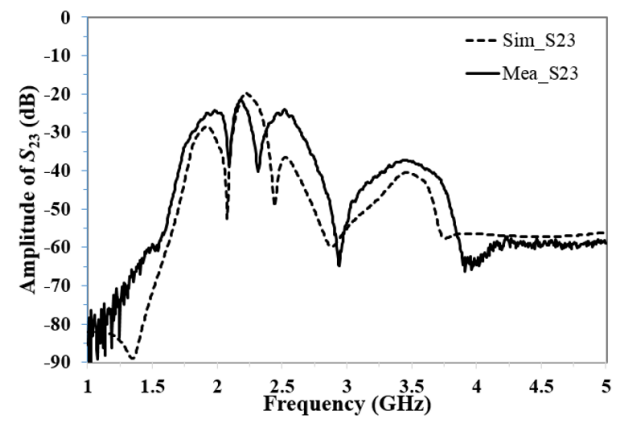

(c) Comparison of isolation $\left(S_{23}\right)$ response of the diplexer.

Fig. 7. Measured and simulated frequency responses of the diplexer.

\section{Design of Tri-band Bandpass Filter}

The triple-band bandpass filter is formed by two resonators, which consist of quad-mode resonator and dualmode resonator, as shown in Fig. 8(a). Note that each filter can be designed independently to yield the desired passband before combining the three passbands. The center frequencies of the three passbands of the proposed BPF are located at $1.75,2.45$, and $3.50 \mathrm{GHz}$. The fractional bandwidths are determined as $5.71 \%, 4.08 \%$, and $5.71 \%$ respectively. In the design technique, the first step is to determine the dimensions of each resonator, the dimensions are optimized as follows: for the first passband (@1.75 GHz) based on dual-mode resonator, the length $L_{1}^{I}=29.35, L_{2}^{I}=1.65 \mathrm{~mm}$, width $W_{1}^{I}=1.00$, and $W_{2}^{I}=2.00 \mathrm{~mm}$. The quad-mode resonator is designed to resonate at second passband (@2.45 GHz) and third passband (@3.50 GHz), the length $L_{1}=16.50, L_{2}=2.50, L_{3}=0.75$, and $L_{x}=8.50$, width $W_{1}=1.0, W_{2}=1.0, W_{3}=2.0$, and dimension $d_{1}=0.4$ (All dimensions are in $\mathrm{mm}$ ).

The next step is to optimize the combination of the two resonators. The tri-band bandpass filter consists of the dual-mode and quad-mode stub-loaded resonators that share a common via through hole where the dimension of via hole is fixed at $0.6 \mathrm{~mm}$.

The last step is to provide external quality factor $\left(Q_{\mathrm{e}}\right)$. The length of feed line $\left(L_{\mathrm{f}}\right)$ and the gaps between the feed lines and the resonator $\left(g_{1}, g_{2}\right)$ determine the bandwidth of the three passbands as shown in Fig. 9. It is found that the length of $L_{\mathrm{f}}$ affect the bandwidth of all passband while, the gap $g_{1}$ mainly affect the first passband and $g_{2}$ affect the second and third passband. The geometric parameters are approximately obtained as $L_{\mathrm{f}}=20.45 \mathrm{~mm}$ and $g_{1}=g_{2}=0.30 \mathrm{~mm}$. In term of coupling coefficient, it can be controlled by the length of $L_{2}^{I}$ of the first passband. Thus, the coupling coefficient of the second and the third passband can be controlled by the length of $L_{3}$ and $L_{x}$ respectively.

The simulated and measured results are illustrated in Fig. 8(b). The three passband frequencies are located at $1.75,2.45$ and $3.50 \mathrm{GHz}$. The minimum insertion loss is measured at 1.47, 1.92 and $1.96 \mathrm{~dB}$, respectively. All passband return losses are better than $12 \mathrm{~dB}$. In the measured results, more than $18 \mathrm{~dB}$ rejection levels outside the passbands is achieved, that contribute to the selectivity of the passband. From the photograph of the fabricated tri-band bandpass filter, the overall size of the fabricated circuit is $22.50 \times 26.25 \mathrm{~mm}$, i.e., about $0.18 \lambda_{\mathrm{g}} \times 0.20 \lambda_{\mathrm{g}}$, where $\lambda_{\mathrm{g}}$ is the guided wavelength on the substrate at the center frequency of first passband. Table 3 summarized the comparisons of the proposed tri-band BPF and other reported tri-band filters. The presented tri-band BPF is the average advantages of compact size and flexible control of passband locations and bandwidths.

\begin{tabular}{|c|c|c|c|c|}
\hline Ref. & CF $(\mathbf{G H z})$ & FBW $(\%)$ & IL $(\mathbf{d B})$ & Size $\left(\lambda_{\mathrm{g}} \times \lambda_{\mathrm{g}}\right)$ \\
\hline$[7]$ & $\begin{array}{c}1.37 / 2.43 \\
/ 3.53\end{array}$ & $\begin{array}{c}4.4 / 5.9 \\
/ 2.7\end{array}$ & $\begin{array}{c}1.7 / 1.8 \\
/ 2.5\end{array}$ & $0.26 \times 0.13$ \\
\hline$[8]$ & $\begin{array}{c}2.50 / 3.50 \\
/ 5.80\end{array}$ & $\begin{array}{c}13.2 / 3.1 \\
/ 3.5\end{array}$ & $\begin{array}{c}0.8 / 2.3 \\
/ 2.4\end{array}$ & $0.18 \times 0.38$ \\
\hline$[9]$ & $\begin{array}{c}1.84 / 2.45 \\
/ 1.98\end{array}$ & $\begin{array}{c}4.9 / 3.5 \\
/ 5.7\end{array}$ & $\begin{array}{c}0.9 / 1.6 \\
/ 0.8\end{array}$ & $0.22 \times 0.27$ \\
\hline$[10]$ & $\begin{array}{c}2.41 / 3.56 \\
/ 5.29\end{array}$ & $\begin{array}{c}6.2 / 12.2 \\
/ 11.8\end{array}$ & $\begin{array}{c}1.9 / 1.4 \\
/ 1.5\end{array}$ & $0.23 \times 0.13$ \\
\hline$[11]$ & $\begin{array}{c}1.92 / 3.50 \\
/ 5.76\end{array}$ & $\begin{array}{c}6.4 / 4.0 \\
/ 2.4\end{array}$ & $\begin{array}{c}0.9 / 1.8 \\
/ 1.9\end{array}$ & $0.09 \times 0.10$ \\
\hline$[12]$ & $\begin{array}{c}1.25 / 3.51 \\
/ 6.82\end{array}$ & $\begin{array}{c}24.4 / 18.3 \\
/ 13.8\end{array}$ & $\begin{array}{c}0.4 / 0.4 \\
/ 1.2\end{array}$ & $0.16 \times 0.15$ \\
\hline This & $1.75 / 2.45$ & $5.7 / 4.1$ & $1.4 / 1.9$ & $0.18 \times 0.20$ \\
work & $/ 3.50$ & $/ 5.7$ & $/ 1.9$ & 0.13 \\
\hline
\end{tabular}

Tab. 3. Comparisons between the proposed filter and other triband filters. 


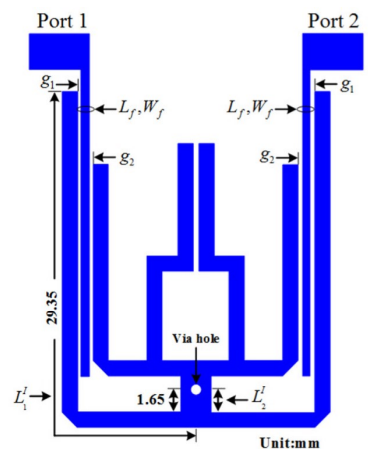

(a) Configuration of tri-band BPF

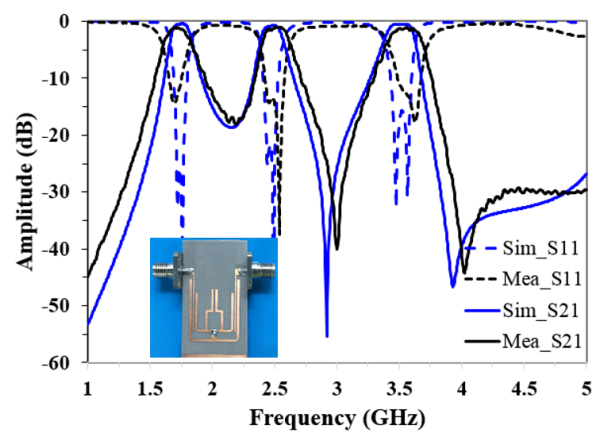

(b) Measured and simulated frequency responses of the tri-band BPF.

Fig. 8. Layout and responses of the proposed BPF.

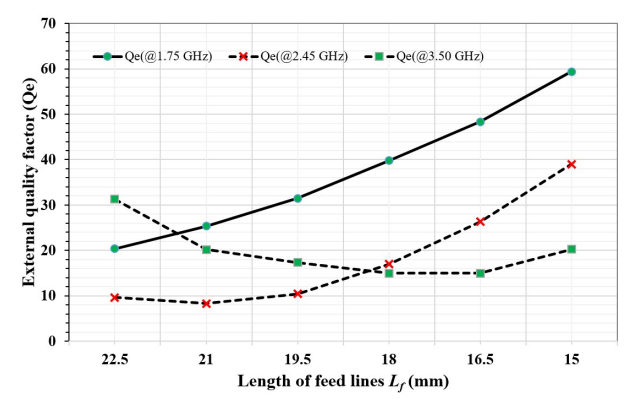

Fig. 9. Simulated $Q_{\mathrm{e}}$ versus length of feed line $\left(L_{\mathrm{f}}\right)$ with fixed coupling gap $\left(g_{1}, g_{2}=0.3 \mathrm{~mm}\right)$ for tri-band BPF.

\section{Conclusion}

In this design, a compact of quad-mode resonator has been proposed for multi-band operation with practically compact size. The resonator has the benefits of flexibility to independently realize different operating bands. For demonstration purpose, two experimental examples, including a quadchannel diplexer and a triple band bandpass filter have been designed and fabricated using microstrip technology. The diplexer is formed by two dual-band BPFs based on quadmode structure. It has the properties of compact size, high selectivity, and good in-band isolation. The triple-band BPF has been designed using the dual-mode resonators and the parallel quad-mode resonator with a common via hole. The three second-order of resonators can be independently designed, flexibly tuned and, thus, save the occupied circuit spaces. The measured results are all in good agreement with simulated predictions. As a result, these compact size diplexer and bandpass filter are suitable for multi-band and multi-service applications.

\section{References}

[1] ZHANG, L. Z., WU, B., QIU, F. Compact six-band triplexer using stub-loaded stepped impedance resonators. Electronics Letters, 2014, vol. 50, no. 16, p. 1143-1145. DOI: 10.1049/el.2014.1320

[2] CHEN, Y. W., WU, H. W., DAI, Z. J., SU, Y. K. Design of compact six-channel diplexer. IEEE Microwave and Wireless Components Letters, 2016, vol. 26, no. 10, p. 792-794. DOI: 10.1109/LMWC.2016.2604868

[3] JIANG, W., HUANG, Y., WANG, T., PENG, Y., WANG, G. Microstrip balanced quad-channel diplexer using dual-open/short-stub loaded resonator. In Proceedings of IEEE MTT-S International Microwave Symposium Digest (IMS). San Francisco (USA), 2016, p. 1-3. DOI: 10.1109/MWSYM.2016.7540232

[4] LEE, J., LIM, Y. Compact dual-band bandpass filter with good frequency selectivity. Electronics Letters, 2011, vol. 47, no. 25, p. 1376-1377. DOI: 10.1049/el.2011.2702

[5] CHEN, F. C., CHU, Q. X., LI, Z. H., WU, X. H. Compact dualband bandpass filter with controllable bandwidths using stub-loaded multiple-mode resonator. IET Microwaves Antennas \& Propagation, 2012, vol. 6, no. 10, p. 1172-1178. DOI: 10.1049/iet-map.2011.0523

[6] JIANG, W., SHEN, W., WANG, T., et al. Compact dualband filter using open/short stub loaded stepped impedance resonators (OSLSIRs/SSLSIRs). IEEE Microwave and Wireless Components Letters, 2016, vol. 26, no. 9, p. 672-674. DOI: 10.1109/LMWC.2016.2597179

[7] LAN, S. W., WENG, M. H., CHANG, S. J., et al. A tri-band bandpass filter with wide stopband using asymmetric stub-loaded resonators. IEEE Microwave and Wireless Components Letters, 2015, vol. 25, no. 1, p. 19-21. DOI: 10.1109/LMWC.2014.2365739

[8] WEI, F., GUO, Y. J., QIN, P. Y., SHI, X. W. Compact balanced dualand tri-band bandpass filters based on stub loaded resonators. IEEE Microwave and Wireless Components Letters, 2015, vol. 25, no. 2, p. 76-78. DOI: 10.1109/LMWC.2014.2370233

[9] ZHANG, X. Y., XUE, Q., HU, B. J. Planar tri-band bandpass filter with compact size. IEEE Microwave and Wireless Components Letters, 2010, vol. 20, no. 5, p. 262-264. DOI: 10.1109/LMWC.2010.2045583

[10] CHU, Q. X., WU, X. H., CHEN, F. C. Novel compact tri-band bandpass filter with controllable bandwidths. IEEE Microwave and Wireless Components Letters, 2011, vol. 21, no. 12, p. 655-657. DOI: 10.1109/LMWC.2011.2172593

[11] WEI, X., WANG, P., GAO, P., et al. Compact tri-band bandpass filter using open stub loaded tri-section $\lambda / 4$ stepped impedance resonator. IEEE Microwave and Wireless Components Letters, 2014, vol. 24, no. 8, p. 512-514. DOI: 10.1109/LMWC.2014.2318899

[12] XU, J., WU, W., MIAO, C. Compact microstrip dual-/tri-/quadband bandpass filter using open stubs loaded shorted steppedimpedance resonator. IEEE Transactions on Microwave Theory and Techniques, 2013, vol. 61, no. 9, p. 3187-3199. DOI: 10.1109/TMTT.2013.2273759

[13] GAO, L., ZHANG, X. Y. High-selectivity dual-band bandpass filter using a quad-mode resonator with source-load coupling. IEEE Microwave and Wireless Components Letters, 2013, vol. 23, no. 9, p. 474-476. DOI: 10.1109/LMWC.2013.2274995 
[14] GAO, L., ZHANG, X. Y., HU, B. J., XUE, Q. Novel multi-stub loaded resonators and their applications to various bandpass filters. IEEE Transactions on Microwave Theory and Techniques, 2014, vol. 62, no. 5, p. 1162-1172. DOI: 10.1109/TMTT.2014.2314680

[15] CHEN, C. F., HUANG, T. Y., CHOU, C. P., WU, R. B. Microstrip diplexers design with common resonator sections for compact size, but high isolation. IEEE Transactions on Microwave Theory and Techniques, 2006, vol. 54, no. 5, p. 1945-1952. DOI: 10.1109/TMTT.2006.873613

[16] CHEN, C. F., SHEN, T. M., HUANG, T. Y., WU, R. B. Design of multimode net-type resonators and their applications to filters and multiplexers. IEEE Transactions on Microwave Theory and Techniques, 2011, vol. 59, no. 4, p. 848-856. DOI: 10.1109/TMTT.2011.2109392

[17] WU, H. W., HUANG, S. H., CHEN, Y. F. Design of new quadchannel diplexer with compact circuit size. IEEE Microwave and Wireless Components Letters, 2013, vol. 23, no. 5, p. 240-242. DOI: 10.1109/LMWC.2013.2253314

[18] CHEN, C. F., LIN, C. Y., TSENG, B. H., CHANG, S. F. A compact microstrip quad-channel diplexer with high-selectivity and highisolation performances. In Proceedings of IEEE MTT-S International Microwave Symposium Digest (IMS). Tampa (USA), 2014, p. 1-3. DOI: 10.1109/MWSYM.2014.6848271

[19] LUO, D., CHEN, F. C., QIU, J. M., CHU, Q. X. Design of quadchannel diplexer using short stub loaded resonator. In Proceedings of IEEE International Wireless Symposium (IWS 2015). Shenzhen (China), 2015, p. 1-4. DOI: 10.1109/IEEE-IWS.2015.7164533

\section{About the Authors ...}

Sugchai TANTIVIWAT was born in Nakhon Si Thammarat, Thailand, on January 25, 1985. He received the B.S. degree in Electrical Engineering-Telecommunication from Walailak University, Nakhon Si Thammarat, Thailand, in 2007, the M.S. degree in Technical Education (Electrical Technology) from King Mongkut's University of Technology North Bangkok, Bangkok, Thailand, in 2010, and is currently working toward the Ph.D. degree in communication engineering at Universiti Malaysia Perlis, Perlis, Malaysia. His research interests include the design of microwave filters and associated RF modules for microwave applications.
Siti Zuraidah IBRAHIM was born in Limbang, Sarawak, Malaysia in 1981. She has a Bachelor of Engineering in Telecommunication from the University of Malaya, Malaysia in 2004 and Master of Engineering from University Technology of Malaysia in 2008. She received her Ph.D. degrees from University of Queensland Australia in 2012. She is currently working as a senior lecturer in the School of Computer and Communication Engineering at Universiti Malaysia Perlis, Malaysia. Most of her research interest is related to microwave components and its application.

Mohammad Shahrazel RAZALLI was born in Teluk Intan, Perak, Malaysia in 1971. He received Diploma in Electrical and Electronic Engineering from Mara Institute of Technology Malaysia in 1993, Bachelor of Engineering (Honours) in Electronic Engineering from University of Leeds, United Kingdom in 1995, Master of Science in Communication and Network Engineering from Universiti Putra Malaysia in 2006. He was a Leader Designer of Electronic Circuit and Printed Circuit Board in Yamaha Electronic Manufacturing, Research and Development from 1997 to 2003. In January 2010, he joined the School Computer and Communication Engineering, Universiti Malaysia Perlis, where he was a senior lecture. He was appointed as the Program Chair Person at School Computer and Communication Engineering from February 2010 to February 2013. His research interests are signal amplifiers (high and low frequencies), radio frequency and microwave circuits (active and passive circuits). Since 2003, he has been involved in electronic circuit design and electromagnetic field specializing in radio frequency transceiver and microwave filters. He has authored and co-authored over 40 scientific papers in journals and conference proceedings. Currently, he has received citations over 253 times and his H-index is 9 based on the Scopus database. He is also a member of Graduate Technologist and Professional member of Malaysia Board of Technologist. He has been awarded with excellent senior lecturer in 2011 by the School Computer and Communication Engineering Universiti Malaysia Perlis. 